\title{
Cross-linking of CD81 by HCV-E2 protein inhibits human intrahepatic plasmacytoid dendritic cells response to CpG-ODN
}

\author{
Zhengkun Tua, ${ }^{a}$, Ping Zhang ${ }^{b}$, Haijun Li ${ }^{\mathrm{a}}$, Junqi Niuc, Xia Jin ${ }^{\mathrm{d}}$, and Lishan Sua,e \\ anstitute of Translational Medicine, The First Hospital, Jilin University, Changchun, China \\ ${ }^{b}$ Department of Surgery, The First Hospital, Jilin University, Changchun, China \\ 'Department of Medicine, The First Hospital, Jilin University, Changchun, China \\ dInstitute Pasteur of Shanghai, Chinese Academy of Science, Shanghai 200025, China \\ eLineberger Comprehensive Cancer Center, School of Medicine, University of North Carolina at \\ Chapel Hill, Chapel Hill, NC 27599, USA
}

\begin{abstract}
Plasmacytoid dendritic cells (pDCs) are reported to be defective in HCV-infected patients, the mechanisms of which remain poorly understood. We isolated liver derived mononuclear cells (LMNCs) and pDCs from normal liver tissues of benign tumor dissections and liver transplant donors. Isolated pDCs and LMNCs were cultured with precoated $\mathrm{HCV}$ envelop protein $\mathrm{E} 2$ (HCVE2) or anti-CD81 mAb in the presence of CpG-ODN. Our results show that cross-linking of CD81 by either HCV-E2 or anti-CD81 mAb inhibits IFN-a secretion in CpG-induced pDCs; downregulates HLA-DR, CD80 and CD86 expression in pDCs; and suppresses CpG-ODN induced proliferation and survival of pDCs. The blockade of CD81 by soluble anti-CD81 antibody restores pDCs response to CpG-ODN. These results suggest that HCV E2 protein interacts with CD81 to inhibit pDC maturation, activation, and IFN-a production, and may thereby contribute to the impaired innate anti-viral immune response in HCV infection.
\end{abstract}

\section{Keywords}

Plasmacytoid dendritic cells (pDCs); Hepatitis C virus envelop protein (HCV-E); $\mathrm{CpG}$ oligodeoxynucleotides (CpG-ODN); Toll-like receptor 9 (TLR9); Cross-linking

\section{Introduction}

$\mathrm{HCV}$ readily establishes persistent hepatic infection in humans and is a major cause of chronic liver diseases worldwide. A number of possible factors contribute to its persistence, including impairment of the host immune response [1]. The precise mechanisms employed by HCV to promote chronic infections remain poorly understood.

It has been proposed that suboptimal or failed antigen presentation during chronic $\mathrm{HCV}$ infection may be responsible for depressed antiviral T-cell responses. Dendritic cells (DCs) are the most potent professional antigen presenting cells (APC) that play a pivotal role in the

(C) 2013 Elsevier Inc. All rights reserved.

*Corresponding author. Address: Institute of translational medicine, The First Hospital, Jilin University, 519 E. Minzhu Ave.,

Changchun 130061, China., tuzhengkun@hotmail.com (Z. Tu).

Conflict of interest

The authors declare that they have no conflict of interest. 
initiation and maintenance of CD4+ and CD8+ T-cell responses. There are two distinct subpopulations of DCs: the myeloid DCs (mDCs) and the plasmacytoid DCs (pDCs). pDCs are innate immune cells that circulate in the blood and lymphoid tissues, and are specialized to produce copious amounts of type I IFNs, IFN- $\alpha$ and IFN- $\beta$, in response to stimulation by virus-associated single-stranded RNA and unmethylated CpG DNA through the engagement of the Toll-like receptors TLR7 and TLR9 within the endosomal compartment [2-4]. HCV virions have a poor capacity to stimulate TLR7 and TLR9, and additionally impair pDC production of I FN-a in response to synthetic TLR9 agonist but not TLR7 agonists [5,6].

It has been extensively reported that pDCs show a striking deficit in HCV-infected patients [6-8], the mechanisms of which remain to be understood. In most previous reports, dysfunction of pDCs from chronic $\mathrm{HCV}$ infected patients has been demonstrated in peripheral blood $[7,8]$. However, since immune responses to HCV are focused in the liver, changes in blood pDCs may not reflect what is happening locally at the site of hepatic infection. It has been demonstrated that an enrichment of DCs occurs in the liver as compared with blood in chronic HCV infected patients [7,8]. In HCV-infected livers, a combination of enhanced $\mathrm{mDCs}$ function and reduced numbers of $\mathrm{pDCs}$ may contribute to viral persistence in the face of persistent inflammation [9].

In the present study, we isolated liver derived mononuclear cells (LMNCs) and purified pDCs from normal liver tissues of benign tumor dissections and liver transplant donors. The results we obtained show that cross-linking of CD81 by incubation with either HCV-E2 or anti-CD81 mAb inhibits IFN-a secretion in CpG-induced pDCs; down-regulates HLA-DR, CD80 and CD86 expression in pDCs; and suppresses CpG-ODN induced proliferation and survival of pDCs. The blockade of CD81 by soluble anti-CD81 antibody restores pDCs response to $\mathrm{CpG}-\mathrm{ODN}$. Collectively, these results reveal some potential molecular mechanisms by which HCV establishes chronic hepatic infection.

\section{Materials and methods}

\subsection{Human liver tissue}

Human liver tissue was obtained from the Liver Unit of the First Hospital of Jilin University. Normal human liver tissue was isolated from either spare donor tissue intended for transplantation or from normal liver tissue resected from patients having benign hepatic tumors. All human tissue samples were collected with local research ethics committee approval and patient consent.

\subsection{Isolation of liver derived mononuclear cells (LMNCs) from human liver tissue}

Fresh liver tissues were cut into small pieces, washed repeatedly in PBS $+10 \%$ FCS until no further blood or bile was visible in the washings, and resuspended in RPMI-1640 with 10\% FCS. They were then homogenized with gentleMACS processor (Miltenyi Biotec), filtered through $70 \mu \mathrm{m}$ nylon mesh, washed in RPMI-1640 with $10 \%$ FCS, and then layered onto Lymphoprep and centrifuged at $600 \mathrm{~g}$ for $30 \mathrm{~min}$. Mononuclear cells were aspirated from the interface, washed and then resuspended in complete RPMI-1640 medium (cRPMI-1640). LMNCs were isolated from liver transplant donors as we have described previously [10-13].

\subsection{Purification of $\mathrm{pDCs}$}

pDCs were purified from LMNCs by BDCA-4 microbeads (Miltenyi) according to the manufacturer's instructions. The purity of the isolated pDCs was verified as being $>90 \%$ with BDCA-2 antibody. 


\subsection{Immobilized E2 and CD81 antibody, and cell culture}

The effects of CD81 cross-linking were investigated using a microtiter culture system as described previously [14]. Briefly, microtiter plates (EIA/RIA plate; Corning Inc.) were coated with either anti-CD $81 \mathrm{mAb}(5 \mu \mathrm{g} / \mathrm{ml})$ or HCV-E2 in sodium bicarbonate buffer $\mathrm{pH}$ 8.2. The plates were incubated overnight at $4{ }^{\circ} \mathrm{C}$, and washed three times with PBS. When immobilizing HVC-E2 onto microtiter wells, the wells were first coated with anti-HCV-E2 $\mathrm{mAb}(5 \mu \mathrm{g} / \mathrm{ml})$. These wells were then washed and exposed to recombinant HCV-E2 protein $(1 \mu \mathrm{g} / \mathrm{ml})$. Isolated LMNCs and purified pDCs were cultured in the precoated microtiter plates in the presence or absence of various CpG-ODNs or a-CD81.

\subsection{Enzyme-linked immunosorbent assay}

Concentrations of IFN- $a$ in culture supernatants were measured by enzyme-linked immunosorbent assay (ELISA) according to the manufacturer's instructions.

\subsection{Flow cytometry}

Cells were stained and analyzed by flow cytometry (FACScan; BD Biosciences, San Jose, CA). FITC-labeled anti-human CD81, allophycocyanin anti-human BDCA-2, Phycoerythrin (PE)-labeled anti-human CD123, Per-CP-labeled anti-human CD80, CD86, HLA-DR antibodies were purchased from eBioscience (San Diego, CA). Data were analyzed using FlowJo software (Treestar, Ashland, OR).

\subsection{Proliferation and cell survival assays}

pDCs proliferation was assessed by ${ }^{3}[\mathrm{H}]$ thymidine incorporation using $2 \times 10^{4}$ cells per well in mAb-coated 96-well plates. Cultures were pulsed after $48 \mathrm{~h}$ with $1 \mathrm{Ci} / \mathrm{well}{ }^{3}[\mathrm{H}]$ thymidine and then incubated for an additional $16 \mathrm{~h}$. The incorporation of ${ }^{3}[\mathrm{H}]$ thymidine in proliferating cells was then measured with a liquid scintillation counter. Cell survival was evaluated by PI staining.

\subsection{Statistical analysis}

All data were analyzed and found to be significant using the D'Agostino and Pearson omnibus normality test. Mean values were compared using either a paired t test ( 2 groups) or ANOVA ( $>2$ groups), followed by Bonferroni correction for multiple comparison test. $P$ values $<0.05$ were considered significant. All statistical tests were performed with Prism software (GraphPad, San Diego, CA).

\section{Results}

\subsection{Human hepatic pDCs express CD81}

It has been reported that $\mathrm{CD} 81$ molecules are required for $\mathrm{HCV}$ entry into hepatoma cell lines [15-17]. CD81 acts as both an HCV attachment receptor with high affinity for HCV$\mathrm{E} 2$ and as a native functional component of signal transduction complexes on the cell surface of lymphocytes [17-19]. We first evaluated whether freshly isolated human intrahepatic cells including pDCs express this receptor. As shown in Fig. 1, most LMNCs and pDCs express CD81 molecules on their surface.

\subsection{Cross-linking of CD81 by HCV-E2 or specific antibody inhibits A-type CpG-induced pDCs IFN- $\alpha$ secretion}

To investigate whether HCV-E2 protein can modulate pDCs in HCV infection, we immobilized HCV-E2 and anti-CD81 mAb separately on a microtiter plate culture system as previously described [14]. LMNCs and purified pDCs were separately cultured in the 
precoated microtiter plates for $24 \mathrm{~h}$ in the presence of an A-type CpG-ODN, CpG-2216, or the control CpG-2243. As shown in Fig. 2A, CpG-2216 induces LMNCs to produce an elevated amount of IFN-a, whereas the CpG-2243 control does not. Cross-linking of CD81by either HCV-E2 or anti-CD81 mAb inhibits IFN-a production in these CpG-2216 induced LMNCs. Blockade of CD81 with soluble anti-CD81 antibody (a-CD81) restores IFN-a production by CpG-2216 induced LMNCs. As shown in Fig. 2B, pure pDCs produce an elevated amount of IFN-a $(10180 \pm 1650 \mathrm{pg} / \mathrm{ml})$ in response to CpG-2216. Cross-linking of CD81 by either HCV-E2 or anti-CD81 mAb significantly inhibits IFN-a production in the pDCs $\left(2706 \pm 234\right.$ and $3167 \pm 165 \mathrm{pg} / \mathrm{ml}$, respectively, $\left.{ }^{* *} p<0.01\right)$. Soluble a-CD81 blocks HCV-E2 cross-linking to partially restore IFN-a production in the CpG-2216 induced pDCs $\left(7632 \pm 898 \mathrm{pg} / \mathrm{ml},{ }^{*} p<0.05\right)$.

\subsection{Cross-linking CD81 with HCV-E2 or specific antibody inhibits CpG-OGN induced pDCs maturation}

To explore the effect of HCV-E2 on pDCs maturation, purified pDCs were cultured in precoated microtiter plates in the presence of a B - type CpG-ODN, CpG-2006, for $48 \mathrm{~h}$. Surface markers of DC maturation were analyzed by flow cytometry. As shown in Fig. 3A and B, CpG-2006 induced HLA-DR (MFI: $214 \pm 65$ ), CD86 (MFI: $78 \pm 16$ ), and CD80 (MFI: $35 \pm 7.8$ ) expression on pDCs. Cross-linking CD81 with CD81 mAb or HCV-E2 significantly inhibit HLA-DR (MFI: $134 \pm 25$ and $165 \pm 34$, respectively, ${ }^{*} p<0.05$ ), CD86 (MFI: $39 \pm 13$ and $27 \pm 8.0$, respectively, ${ }^{*} p<0.05$ ), and CD80 (MFI: $19 \pm 4.3$ and $15 \pm 2.5$, respectively, ${ }^{*} p<0.05$ ). Soluble a-CD81 partially restores HLA-DR (MFI:198 \pm 45 ), CD86 (MFI:41 \pm 6.0 ), and CD80 (MFI:33 \pm 6.6 ) expression on pDCs.

\subsection{Cross-linking CD81 with HCV-E2 or specific antibody inhibits CpG-induced pDCs proliferation and survival}

IL-3 is the key cytokine for promoting the generation of pDCs from high IL-3R-expressing plasmacytoid precursor cells, and it ensures their proliferation and survival [20]. In order to evaluate whether HCV-E2 inhibits pDCs proliferation and survival, purified pDCs were cultured with IL-3 and CpG-2006 for 3 days. As shown in Fig. 4A, CpG-2006 synergizes with IL-3 to induce pDCs proliferation $(\mathrm{CPM} \times 1000: 3.19 \pm 0.195)$. However, cross-linking CD81 with anti-CD81 mAb $\left(\mathrm{CPM} \times 1000: 1.25 \pm 0.171,{ }^{* *} p<0.01\right)$ or HCV-E2 $(\mathrm{CPM} \times$ 1000: $\left.1.09 \pm 0.129,{ }^{* *} p<0.01\right)$ inhibited CpG-2006 and IL-3 induced pDCs proliferation. aCD81 blockade of CD81 cross-linking by HCV-E2 partially restores CpG-2006 and IL-3 induced pDCs proliferation (CPM $\left.\times 1000: 2.27 \pm 0.189,{ }^{*} p<0.05\right)$. As shown in Fig. 4B, both IL-3 and CpG-2006 induce pDCs survival (\% living cells: $74.5 \pm 2.81 \%$ and $79.35 \pm$ $2.41 \%$, respectively) by either promoting pDCs proliferation or inhibiting pDCs apoptosis. The results in Fig. 4B also indicate that CpG-2006 induced pDCs survival is inhibited by cross-linking CD81 with anti-CD81 mAb (\% live cells: $\left.28.95 \pm 1.30 \%,{ }^{* *} p<0.01\right)$ or HCVE2 (\% live cells: $27.37 \pm 2.73 \%,{ }^{* *} p<0.01$ ). Soluble a-CD81 blockade of CD81 crosslinking by HCV-E2 partially restores CpG-2006induced pDCs survival (\% live cells: 66.27 $\left.\pm 1.98 \%,{ }^{*} p<0.05\right)$.

\section{Discussion}

$\mathrm{HCV}$ entry into hepatocytes is the first step of a virus life cycle that leads to persistent viral infection. It is a multistep process mediated by HCV envelop glycoproteins E1 and E2 and several host cell surface receptors. The cell surface receptors mainly include tetraspanin protein CD81, SR-BI, LDLR and CLDN1 which is a tight junction protein. Human CD81 is the first receptor identified as being necessary for HCV entry into host cells. CD81 is a widely distributed cell-surface tetraspanin that participates in different molecular complexes on various cell types, including hepatocytes, B lymphocytes, $\mathrm{T}$ lymphocytes, natural killer 
cells and dendritic cells. Consistent with this, we show that both human liver-derived LMNCs and intrahepatic pDCs express a high level of CD81.

Dendritic cells bridge innate and adaptive immunity and play a central role in anti-viral defense. Human pDCs are especially important in viral infections because of their capacity to produce IFN- $a$ in larger amounts than any other cell types. HCV has consequently developed strategies to evade the IFN system. The mechanisms by which HCV is able to modulate the IFN-a response of intrahepatic pDCs has been unclear.

HCV-E2 has previously been shown to bind to the main extracellular loop of CD81, which leads to inhibition of NK cells activation [14,21]. To investigate the outcome of an interaction between HCV-E2 and CD81 on the IFN-a response of human intra-hepatic pDCs, we developed an assay system in which LMNCs or purified pDCs are cultured in microtiter plates coated with either immobilized HCV-E2 or anti-CD81 mAb. Human pDCs express TLR9, which is responsible for recognition of CpG motifs present in bacterial DNA or ODNs. It is now clearly established that the A-type CpG-ODNs can efficiently stimulate IFN-a production by pDCs [22]. In the present study, we stimulated pDCs with CpG-2216 to induce IFN-a production, and demonstrated that cross-linking CD81 with either immobilized HCV-E2 or anti-CD81 mAb, but not soluble HCV-E2 protein, inhibits IFN-a production by $\mathrm{CpG}-2216$ induced pDCs. In agreement with our findings, Zhang s et al. recently reported a novel mechanism for recognition of $\mathrm{HCV}$ in infected hepatoma cells by pDCs which involves the formation of membrane microdomains by CD81- and CD9associated tetraspanin webs and lipid rafts [23]. Therefore, our above results with respect to IFN-a production may provide a potential mechanism by which $\mathrm{HCV}$ is able to evade the IFN driven immune response.

B-type CpG-ODNs elicited only low levels of type I IFN but induced rapid pDCs maturation with increased surface expression of MHC class II and costimulatory molecules (CD80, CD86, CD40) [22]. Maturated pDCs mixed with activated allogeneic T cells potentially produce large amounts of IL-12, including its bioactive form IL-12 p70, to promote Th1 responses [24]. In the present study, the B-type CpG-ODN, CpG-2006, was used to induce pDCs maturation, and we demonstrated that cross-linking CD81 with either immobilized HCV-E2 or immobilzed anti-CD81 mAb, but not soluble HCV-E2 protein, inhibits CpG-2006 induced HLA-DR, CD80 and CD86 expression on pDCs. In addition to their potency for stimulating innate immunity, pDCs can polarize adaptive immune responses against exogenous particulate $\mathrm{Ag}$ [25]. These observations suggest that monovalent binding between HCV-E2 and CD81 per se is insufficient to induce signals that cause defective IFNa production in $\mathrm{pDCs}$.

CpG-ODNs alone can substitute for the cytokine requirement for survival of primary human DCs. CpG-ODNs are even superior to GM-CSF in promoting pDCs survival in tissue culture [26]. It has been reported that the numbers of pDCs were significantly lower in HCV infected patients than in healthy controls [7,27-29], and successful antiviral therapy was able to normalize the number of pDCs in patients [30]. The present study shows that crosslinking of CD81 by either HCV-E2 or anti-CD81 mAb inhibited CpG-2006 and IL-3 induced proliferation and survival of pDCs, and thus may help to explain the treatment success mentioned above.

In summary, HCV may employ envelop protein HCV-E2 to inhibit, maturation, proliferation, survival and IFN-a production in $\mathrm{pDCs}$. This may contribute to impaired innate and adaptive immune response during HCV infection. As yet, we do not know the exact mechanism as to how HCV-E2 interacts with CD81 to inhibit TLR9 signaling in pDCs. It may be that viral particles interact with regulatory receptors on pDCs to impair 
TLR7 and TLR9 signaling and to also downregulate TLR9 gene expression [31-33]. The limited responsiveness of pDCs may be contributing to reduced innate immune responses during chronic $\mathrm{HCV}$ infection and oncogenesis, and the mechanisms revealed above may represent potential targets for new therapeutic interventions.

\section{Acknowledgments}

We would like to thank Dr. Andrew Kenedy (keenidea@hotmail.com) for editorial assistance.

\section{References}

1. Dustin LB, Rice CM. Annu Rev Immunol. 2007; 25:71-99. [PubMed: 17067278]

2. Beignon AS, McKenna K, Skoberne M, Manches O, DaSilva I, Kavanagh DG, Larsson M, Gorelick RJ, Lifson JD, Bhardwaj N. Endocytosis of HIV-1 activates plasmacytoid dendritic cells via Tolllike receptor-viral RNA interactions. J Clin Invest. 2005; 115:3265-3275. [PubMed: 16224540]

3. Heil F, Hemmi H, Hochrein H, Ampenberger F, Kirschning C, Akira S, Lipford G, Wagner H, Bauer S. Species-specific recognition of singlestranded RNA via toll-like receptor 7 and 8 . Science. 2004; 303:1526-1529. [PubMed: 14976262]

4. Latz E, Schoenemeyer A, Visintin A, Fitzgerald KA, Monks BG, Knetter CF, Lien E, Nilsen NJ, Espevik T, Golenbock DT. TLR9 signals after translocating from the ER to CpG DNA in the lysosome. Nat Immunol. 2004; 5:190-198. [PubMed: 14716310]

5. Shiina M, Rehermann B. Cell culture-produc ed hepatitis $\mathrm{C}$ virus impairs plasmacytoid dendritic cell function. Hepatology. 2008; 47:385-395. [PubMed: 18064579]

6. Gondois-Rey F, Dental C, Halfon P, Baumert TF, Olive D, Hirsch I. Hepatitis C virus is a weak inducer of interferon alpha in plasmacytoid dendritic cells in comparis on with influenza and human herpes virus type-1. PLoS One. 2009; 4:e4319. [PubMed: 19183807]

7. Wertheimer AM, Bakke A, Rosen HR. Direct enumeration and functional assessment of circulating dendritic cells in patients with liver disease. Hepatology. 2004; 40:335-345. [PubMed: 15368438]

8. Nattermann J, Zimmermann H, Iwan A, von Lilienfeld-Toal M, Leifeld L, Nischalke HD, et al. Hepatitis C virus E2 and CD81 interaction may be associated with altered trafficking of dendritic cells in chronic hepatitis C. Hepatology. 2006; 44:945-954. [PubMed: 17006905]

9. Lai WK, Curbishley SM, Goddard S, Alabraba E, Shaw J, Youster J, McKeating J, Adams DH. Hepatitis $\mathrm{C}$ is associated with perturbation of intrahepatic myeloid and plasmacytoid dendritic cell function. J Hepatol. 2007; 47:338-347. [PubMed: 17467113]

10. Tu Z, Bozorgzadeh A, Crispe IN, Orloff MS. The activation state of human intrahepatic lymphocytes. Clin Exp Immunol. 2007; 149:186-193. [PubMed: 17511774]

11. Tu Z, Bozorgzadeh A, Pierce RH, Kurtis J, Crispe IN, Orloff MS. TLR-dependent cross talk between human Kupffer cells and NK cells. J Exp Med. 2008; 205:233-244. [PubMed: 18195076]

12. Tu Z, Pierce RH, Kurtis J, Kuroki Y, Crispe IN, Orloff MS. Hepatitis C virus core protein subverts the anti-viral activities of human kupffer cells. Gastroenterology. 2010; 138:305-314. [PubMed: 19769973]

13. Tu Z, Hamalainen-Laanaya HK, Crispe IN, Orloff MS. Synergy between TLR3 and IL-18 promotes IFN- $\gamma$ dependent TRAIL expression in human liver NK cells. Cell Immunol. 2011; 271:286-291. [PubMed: 21802664]

14. Tseng CT, Klimpel GR. Binding of the hepatitis C virus envelope protein E2 to CD81 inhibits natural killer cell functions. J Exp Med. 2002; 195:43-49. [PubMed: 11781364]

15. Cormier EG, Tsamis F, Kajumo F, Durso RJ, Gardner JP, Dragic T. CD81 is an entry coreceptor for hepatitis C virus. Proc Natl Acad Sci USA. 2004; 101:7270-7274. [PubMed: 15123813]

16. Kapadia SB, Barth H, Baumert T, McKeating JA, Chisari FV. Initiation of hepatitis C virus infection is dependent on cholesterol and cooperativity between CD81 and scavenger receptor B type I. J Virol. 2007; 81:374-383. [PubMed: 17050612]

17. Pileri P, Uematsu Y, Campagnoli S, Galli G, Falugi F, Petracca R, Weiner AJ, Houghton M, Rosa D, Grandi G, Abrignani S. Binding of hepatitis C virus to CD81. Science. 1998; 282:938-941. [PubMed: 9794763] 
18. Levy S, Todd S, Maecker H. CD81 (TAPA-1): a molecule involved in signal transduction and cell adhesion in the immune system. Annu Rev Immunol. 1998; 16:89-109. [PubMed: 9597125]

19. Wack A, Soldaini E, Tseng CK, Nuti S, Klimpel GR, Abrignani S. Binding of hepatitis C virus envelope protein E2 to CD81 provides a co-stimulatory signal for human T cells. Eur J Immunol. 2001; 31:166-175. [PubMed: 11169450]

20. Grouard G, Rissoan MC, Filgueira L, Durand I, Banchereau J, Liu YJ. The enigmatic plasmacytoid T cells develop into dendritic cells with interleukin (IL)-3 and CD40-ligand. J Exp Med. 1997; 185:1101-1111. [PubMed: 9091583]

21. Crotta S, Stilla A, Wack A, D’Andrea A, Nuti S, D’Oro U, Mosca M, Filliponi F, Brunetto RM, Bonino F, Abrignani S, Valiante NM. Inhibition of natural killer cells through engagement of CD81 by the major hepatitis C virus envelope protein. J Exp Med. 2002; 195:35-41. [PubMed: 11781363]

22. Verthelyi D, Zeuner RA. Differential signaling by CpG DNA in DCs and B cells: not just TLR9. Trends Immunol. 2003; 24:519-522. [PubMed: 14552833]

23. Zhang S, Kodys K, Babcock GJ, Szabo G. CD81/CD9 tetraspanins aid plasmacytoid dendritic cells in recognition of hepatitis $\mathrm{C}$ virus-infected cells and induction of interferon-alpha. Hepatology. 2012; 10 http://dx.doi.org/10.1002/hep.25827.

24. Krug A, Towarowski A, Britsch S, Rothenfusser S, Hornung V, Bals R, Giese T, Engelmann H, Endres S, Krieg AM, Hartmann G. Toll-like receptor expression reveals CpG DNA as a unique microbial stimulus for plasmacytoid dendritic cells which synergizes with CD40 ligand to induce high amounts of IL-12. Eur J Immunol. 2001; 31:3026-3037. [PubMed: 11592079]

25. Tel J, Lambeck AJ, Cruz LJ, Tacken PJ, de Vries IJ, Figdor CG. Human plasmacytoid dendritic cells phagocytose, process, and present exogenous particulate antigen. J Immunol. 2010; 184:4276-4283. [PubMed: 20304825]

26. Hartmann G, Weiner GJ, Krieg AM. CpG DNA: A potent signal for growth, activation, and maturation of human dendritic cells. Proc Natl Acad Sci USA. 1999; 96:9305-9310. [PubMed: 10430938]

27. Szabo G, Dolganiuc A. Subversion of plasmacytoid and myeloid dendritic cell functions in chronic HCV infection. Immunobiology. 2005; 210:237-247. [PubMed: 16164031]

28. Anthony DD, Yonkers NL, Post AB, et al. Selective impairments in dendritic cell-associated function distinguish hepatitis C virus and HIV infection. J Immunol. 2004; 172:4907-4916. [PubMed: 15067070]

29. Kanto T, Inoue M, Miyatake H, et al. Reduced numbers and impaired ability of myeloid and plasmacytoid dendritic cells to polarize T helper cells in chronic hepatitis $\mathrm{C}$ virus infection. $\mathrm{J}$ Infect Dis. 2004; 190:1919-1926. [PubMed: 15529255]

30. Mengshol JA, Golden-Mason L, Castelblanco N, Im KA, Dillon SM, Wilson CC, Rosen HR. Virahep-C Study Group. Impaired plasmacytoid dendritic cell maturation and differential chemotaxis in chronic hepatitis C virus: associations with antiviral treatment outcomes. Gut. 2009; 58:964-973. [PubMed: 19193669]

31. Lambert AA, Gilbert C, Richard M, Beaulieu AD, Tremblay MJ. The C-type lectin surface receptor DCIR acts as a new attachment factor for HIV-1 in dendritic cells and contributes to trans- and cis-infection pathways. Blood. 2008; 112:1299-1307. [PubMed: 18541725]

32. Cao W, Zhang L, Rosen DB, Bover L, Watanabe G, Bao M, Lanier LL, Liu YJ. BDCA2/Fc epsilon RI gamma complex signals through a novel BCR-like pathway in human plasmacy toid dendritic cells. PLoS Biol. 2007; 5:e248. [PubMed: 17850179]

33. Meyer-Wentrup F, Benitez-Ribas D, Tacken PJ, Punt CJ, Figdor CG, de Vries IJ, Adema GJ. Target ing DCIR on human plasmacytoid dendritic cells results in antigen presentation and inhibits IFN-alpha production. Blood. 2008; 111:4245-4253. [PubMed: 18258799] 


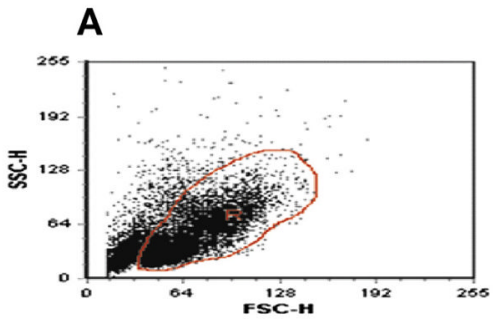

\section{B}

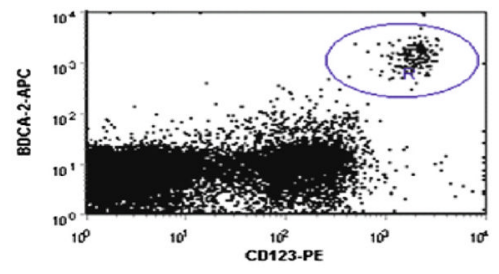

$$
\text { C }
$$

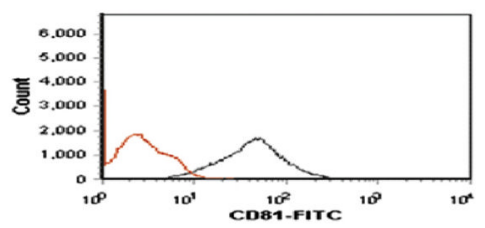

D

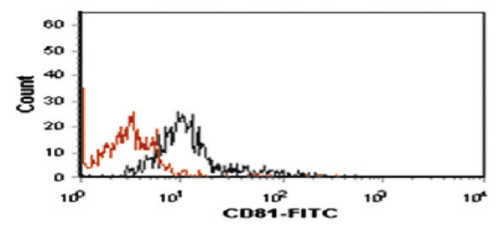

Fig. 1.

CD81 expression in LMNCs and pDCs. LMNCs were isolated from fresh normal liver tissue. CD81 expression was analyzed by flow cytometry on LMNCs (A and C) and pDCs (B and D). Shown is one representative experiment of six. 

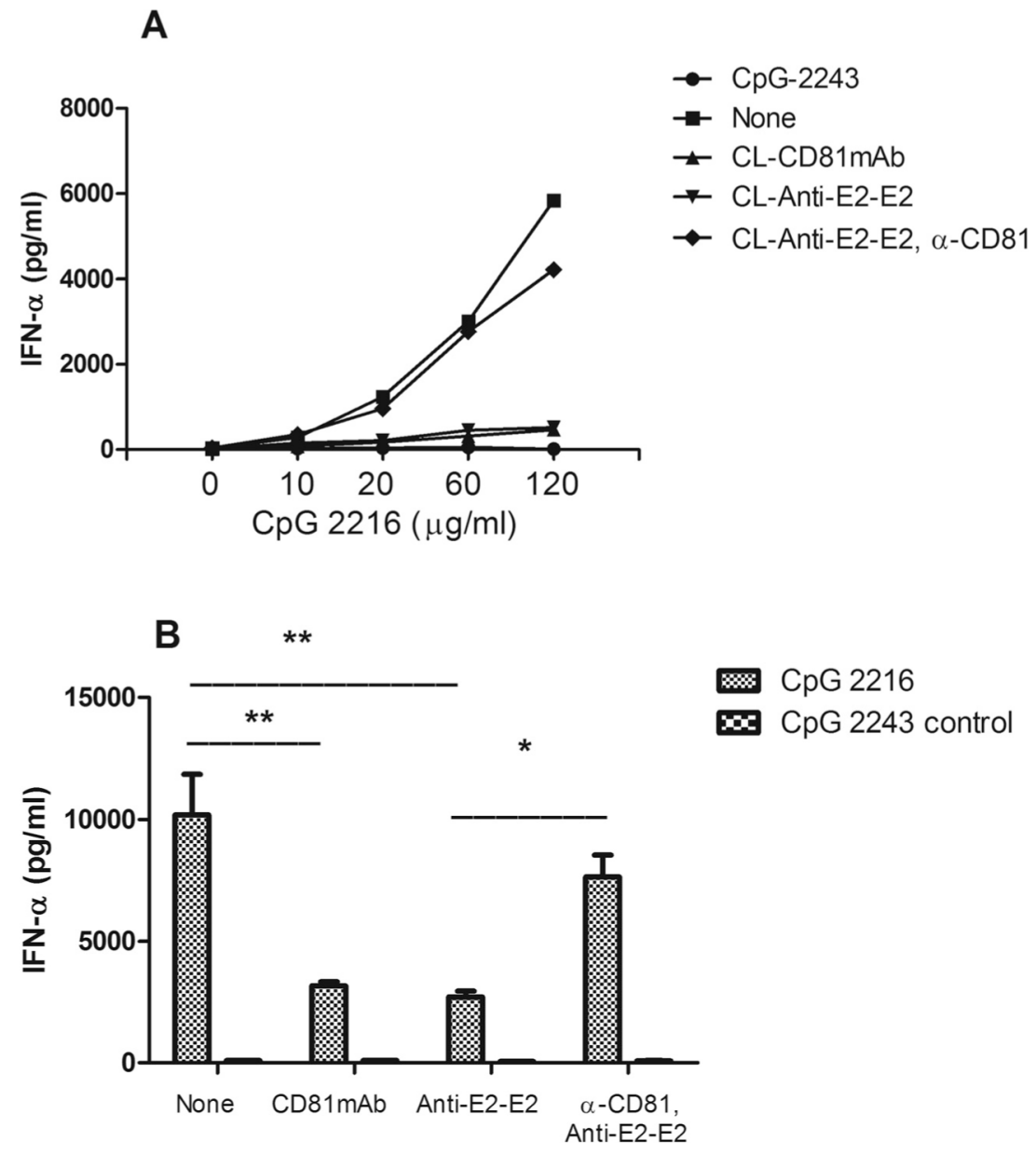

Fig. 2.

CD81 cross-linking inhibits induction of IFN-a release in LMNCs and purified pDCs. (A) Freshly isolated LMNCs were cultured for $24 \mathrm{~h}$ in the presence of serially diluted CpG-2216 or CpG-2243 control in pre-coated microtiter wells containing either immobilized antiCD81 mAb or immobilized HCV-E2 to induce cross-linking, and one instance of blocking by exposure to soluble $\mathrm{a}-\mathrm{CD} 81$ antibody. The supernatants were assayed for IFN-a levels by ELISA. Shown is one representative experiment of six. (B) purified pDCs were cultured for $24 \mathrm{~h}$ in the presence of $20 \mu \mathrm{g} / \mathrm{ml}$ of either CpG-2216 or CpG-2243 control in pre-coated microtiter wells containing either immobilized anti-CD81 mAb or immobilized HCV-E2 to induce cross-linking and one instance of blocking by exposure to soluble a-CD81 antibody. The supernatants were assayed by ELISA for IFN-a levels. The figure shows median levels and standard error from 6 donors $\left({ }^{*} p<0.05,{ }^{* *} p<0.01\right)$. 


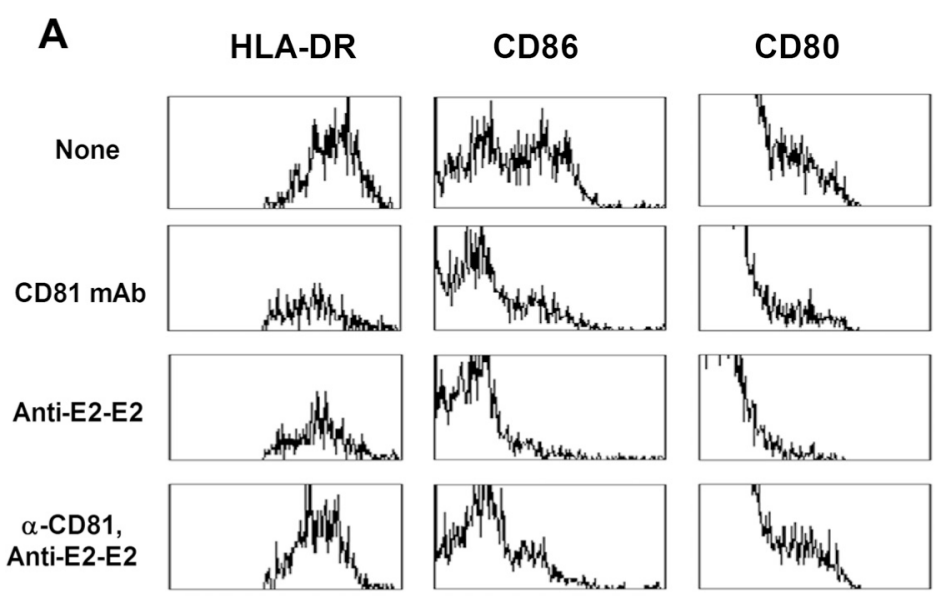

B

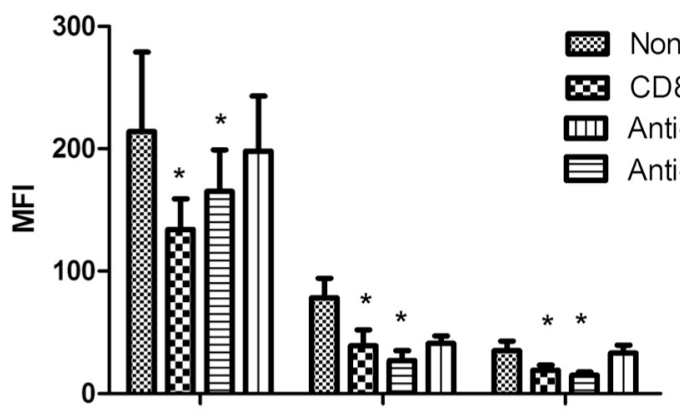

HLA-DR CD86 CD80

Fig. 3.

CD81 cross-linking inhibits CpG-ODNinduced pDC maturation. Purified pDCs were incubated with $50 \mu \mathrm{g} / \mathrm{ml} \mathrm{CpG} 2006$ for $48 \mathrm{~h}$ in presence or absence of CD81 cross-linking with one instance of blocking by exposure to soluble a-CD81 antibody. Surface expression of the indicated molecules was determined by flow cytometry. (A) Shown is one representative experiment of six. (B) Histograms represent the mean and standard error of median fluorescence intensities of 6 experiments from 6 independent donors $\left(^{* *} p<0.05\right)$. 

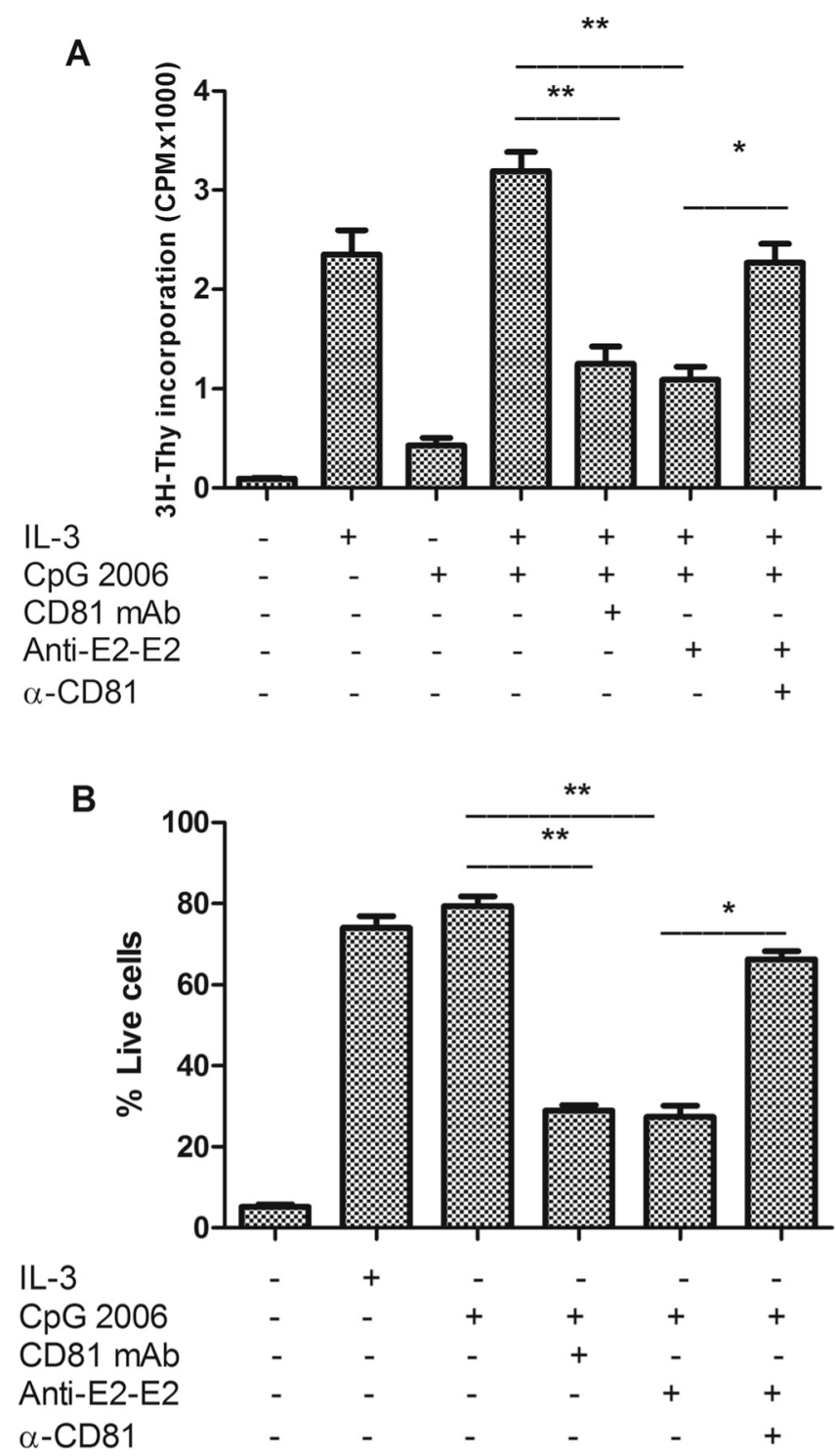

Fig. 4.

CD81 cross-linking inhibits CpG-ODN induced pDC proliferation and survival. Purified pDCs were cultured with IL-3 and/or CpG-2006 for 3 days in the presence or absence of CD81 cross-linking and one instance of blocking by exposure to soluble a-CD81 antibody. (A) ${ }^{3}[\mathrm{H}]$ thymidine incorporation assay was used to measure cell proliferation. (B) PI staining was used to analyze cell survival. The figure shows median levels of experiments from 6 donors $\left({ }^{* *} p<0.01,{ }^{*} p<0.05\right)$. 